$11-24-2008$

\title{
Photoluminescence of 1-D Copper(I) Cyanide Chains: A Theoretical Description
}

\author{
Craig A. Bayse \\ Timothy P. Brewster \\ College of William and Mary \\ Robert D. Pike \\ College of William and Mary, rdpike@wm.edu
}

Follow this and additional works at: https://scholarworks.wm.edu/aspubs

Part of the Physics Commons

\section{Recommended Citation}

Bayse, Craig A.; Brewster, Timothy P.; and Pike, Robert D., Photoluminescence of 1-D Copper(I) Cyanide Chains: A Theoretical Description (2008). Inorganic Chemistry, 48, 174-182.

https://doi.org/10.1021/ic801509t

This Article is brought to you for free and open access by the Arts and Sciences at W\&M ScholarWorks. It has been accepted for inclusion in Arts \& Sciences Articles by an authorized administrator of W\&M ScholarWorks. For more information, please contact scholarworks@wm.edu. 


\title{
Photoluminescence of 1-D Copper(I) Cyanide Chains: A Theoretical Description
}

Craig A. Bayse, ${ }^{* a}$ Timothy P. Brewster, ${ }^{\mathrm{b}}$ and Robert D. Pike ${ }^{* \mathrm{~b}}$

a Department of Chemistry and Biochemistry, Old Dominion University, Hampton Boulevard, Norfolk, Virginia 23529

${ }^{\mathrm{b}}$ Department of Chemistry, College of William and Mary, Williamsburg, VA 23187

\begin{abstract}
Solid copper(I) cyanide occurs as extended one-dimensional chains with interesting photophysical properties. To explain the observed luminescence spectroscopy of $\mathrm{CuCN}$, we report a series of computational studies using short bare and potassium-capped $\left[\mathrm{Cu}_{n}(\mathrm{CN})_{n+1}\right]^{-}(\mathrm{n}$ $=1,2,3,4,5$ and 7) chains as CuCN models. Based upon TD-DFT calculations of these model chains, the excitation transitions in the UV spectrum are assigned as Laporte-allowed $\pi-\pi$ transitions from MOs with $\mathrm{Cu} 3 \mathrm{~d}_{\pi}$ and $\mathrm{CN} \pi$ character to empty MOs with $\mathrm{Cu} 4 \mathrm{p}$ and $\mathrm{CN} \pi^{*}$ character. Transitions between the HOMO $\left(3 \mathrm{~d}_{\mathrm{z}}\right)$ and LUMO $\left(\mathrm{Cu} 4 \mathrm{p}\right.$ and $\left.\mathrm{CN} \pi^{*}\right)$ are symmetry forbidden and are not assigned to the bands in the excitation spectrum. The emission spectrum is assumed to arise from transitions between the lowest triplet excited state and the ground state singlet. The lowest energy triplet for the model networks has a bent structure due to distortions to remove the degeneracies in the partially occupied MOs of the linear triplet. The $\mathrm{S}_{0}-\mathrm{T}$ gap for the bent triplet chains is consistent with the emission wavelength for bulk $\mathrm{CuCN}$.
\end{abstract}

\footnotetext{
*corresponding authors: cbayse@odu.edu ; rdpike@wm.edu
} 


\section{Introduction}

Organic and inorganic solid state luminescent materials are currently a subject of active research since they are potentially important in device displays. ${ }^{1}$ Luminescent solids also have potential application in molecular sensing systems, since chemisorption of small molecules has been shown to alter luminescence behavior. ${ }^{2}$ In reference to these applications, we are interested in the luminescence of copper(I) cyanide and its amine derivatives. ${ }^{3}$ While $\mathrm{CuCN}$ luminesces at the border of the $\mathrm{UV}$ and the visible, the amine-bearing $\mathrm{CuCN}$ complexes emit in the visible region. Nevertheless, the photophysical behavior of the $\mathrm{CuCN}$-amine networks appears to be closely related to that of $\mathrm{CuCN}$ itself. ${ }^{3}$ Therefore, in the present contribution we have undertaken a computational examination of $\mathrm{CuCN}$.

Structurally, copper(I) cyanide is a very unusual inorganic salt. While most inorganic salts form $2 \mathrm{D}$ or $3 \mathrm{D}$ arrays, $\mathrm{CuCN}$ forms unidimensional polymer chains consisting of two-coordinate metal centers and bridging cyano ligands. Two $\mathrm{CuCN}$ phases are known. In both phases carbon and nitrogen sites are crystallographically disordered, thus the chains may be represented as $-\mathrm{X} \equiv \mathrm{X}-\mathrm{Cu}-$ $\mathrm{X} \equiv \mathrm{X}-\mathrm{Cu}-$, where $\mathrm{X}$ represents disordered carbon and nitrogen atoms (Figs 1A and 1B). In the common (and commercial) low temperature modification of $\mathrm{CuCN}$, these chains are wavy $(\mathrm{X}-\mathrm{Cu}-$ $\mathrm{X}=176.7-179.0^{\circ}$ and $\left.\mathrm{Cu}-\mathrm{X}-\mathrm{X}=174.0-179.4^{\circ}\right){ }^{4}$ Alternating rows of undulating chains are offset from one another by $c a .50^{\circ}$. By way of contrast, in the high temperature form of $\mathrm{CuCN}$ the chains are strictly linear $\left(\mathrm{X}-\mathrm{Cu}-\mathrm{X}, \mathrm{Cu}-\mathrm{X}-\mathrm{X}=180.0^{\circ}\right)$ and all chains are parallel to one another. ${ }^{5}$ Metalmetal interactions are common for $\mathrm{Cu}(\mathrm{I})$ compounds; ${ }^{6}$ such contacts are typically judged by comparison to the sum of two $\mathrm{Cu}$ van der Waals radii, $2.8 \AA$. However, the nearest $\mathrm{Cu} \cdots \mathrm{Cu}$ distances in low and high temperature forms of $\mathrm{CuCN}$ are $c a .3 .09$ and $3.78 \AA$, respectively. When $\mathrm{CuCN}$ is reacted with simple amines $(\mathrm{L})$, the resulting $\mathrm{CuCN}-\mathrm{L}$ products are $1 \mathrm{D}$ chains in which $\mathrm{Cu}$ is 3- or 4-coordinate. ${ }^{7}$ Bridging diamine ligands cross-link $\mathrm{CuCN}$ chains to form $2 \mathrm{D}$ or $3 \mathrm{D}$ networks. ${ }^{3}$ In many cases these networks are penetrated by independent $\mathrm{CuCN}$ chains which thread through the pores in the network.

As indicated above, copper(I) cyanide is a luminescent material, showing a broad excitation feature in the near UV and intense emission at the UV/visible borderline $\left(\lambda_{\max }=392 \mathrm{~nm}\right){ }^{3 \mathrm{c}}$ Surprisingly, CuCN luminescence has remained essentially unstudied to date. Studies in aqueous solution by Stevenson have shown photoluminescent behavior in $\left[\mathrm{Cu}(\mathrm{CN})_{2}\right]^{-8} \mathrm{UV}$ photoexcitation of this anion leads to an interesting range of behaviors. The primary fate of 
singlet $\left[\mathrm{Cu}(\mathrm{CN})_{2}\right]^{-*}$ is electron ejection. However, competing with this process is intersystem crossing producing a triplet state. The resulting triplet species may undergo electron ejection or react with $\left[\mathrm{Cu}(\mathrm{CN})_{2}\right]^{-}$to form an excimer. In the presence of certain nucleophilic species, such as halide ions or amines, $\left[\mathrm{Cu}(\mathrm{CN})_{2}\right]^{-*}$ reacts to form exciplexes. A number of possible photophysical causes for luminescence in $\mathrm{Cu}(\mathrm{I})$ complexes are recognized. ${ }^{9}$ These include metal to ligand charge transfer (MLCT), halide to ligand charge transfer (XLCT), metal cluster centered transitions (CC), single metal centered transitions (MC) and ligand centered transitions (LC). Since cyanide is the only ligand in CuCN, XLCT is obviously not a valid option, and transitions of the LC type may also be ruled out since cyanide has a large band gap. The absence of close $\mathrm{Cu} \cdot \mathrm{Cu}$ contacts argues against $\mathrm{CC}$ transitions in $\mathrm{CuCN}$. Nevertheless, even though $\mathrm{CC}$ behavior is unlikely in the case of $\mathrm{CuCN}$ itself, a number of $\mathrm{CuCN}$-amine networks contain $\mathrm{Cu}{ }^{\cdots} \mathrm{Cu}$ of $<2.8 \AA{ }^{3}{ }^{3,10}$ Transitions of CC nature should not be completely ruled out in these cases.

Elimination of XLCT, LC and CC phenomena leaves the MC and MLCT as possible photophysical sources of luminescence behavior in $\mathrm{CuCN}$. MC transitions are dependent only on the metal orbitals while MLCT is modulated by the ligand orbitals. Therefore, the question is: What role does cyanide play in the donor and acceptor states associated with $\mathrm{CuCN}$ luminescence? In the current study, we sought to determine the relative importance of MC, specifically $3 d \rightarrow(4 p, 4 s)$, and MLCT contributions in the observed luminescence behavior in $\mathrm{CuCN}$ using density functional theory (DFT) and time-dependent DFT (TD-DFT). The latter is an economical method for determining electronic transitions in chemical systems with an accuracy that often rivals the highest level $a b$ initio methods. ${ }^{11}$ TD-DFT has been applied to a number of extended $\pi$ systems ${ }^{12,13,14,15,16}$ and luminescent transition metal complexes ${ }^{17}$ with notable problems describing CT states.

\section{Theoretical Methods}

Models of the copper(I) cyanide chains were optimized using Gaussian $03^{18}$ at the DFT level using the SVWN, ${ }^{19}$ BLYP, ${ }^{20,21}$ BP86, ${ }^{20,22} \mathrm{HCTH} / 407^{23}$ and mPW1PW91 ${ }^{24}$ exchangecorrelation (xc) functionals. The copper atoms were represented by the Ermler-Christiansen relativistic effective core potential (RECP) basis $\operatorname{set}^{25}$ modified to include the $4 p$ contractions of Couty and Hall. ${ }^{26}$ Basis sets for the carbon and nitrogen atoms were the split-valence triple- $\zeta$ plus polarization functions (TZVP) representations of Dunning. ${ }^{27}$ The potassium atoms were represented by the Hay-Wadt RECP basis set. ${ }^{28}$ The excitation spectrum of the model chains 
were obtained using TD-DFT to generate all transitions to singlet states less than $5.2 \mathrm{eV}(5.4 \mathrm{eV}$ for the $n=1$ chain). Optimizations and TD-DFT calculations of selected models were also performed using an extended basis set in which the $\mathrm{Cu}$ and $\mathrm{K}$ basis sets were uncontracted, a set of f-type polarization functions were added to $\mathrm{Cu}$ and diffuse functions were added to all atoms except K (BSII).

\section{Results and Discussion}

Geometry optimization. In this study, short bare-anionic and potassium-capped chains of $\mathrm{CuCN}$ are used to model the electronic structure of the solid-state material. These chains are constructed such that all $\mathrm{Cu}(\mathrm{I})$ ions are coordinated by two cyanides $\left(\mathrm{Cu}_{\mathrm{n}}(\mathrm{CN})_{\mathrm{n}+1}\right)$ and constrained to cylindrical symmetry in the ground state $\left(\mathrm{D}_{\infty \mathrm{h}}\right.$ and $\left.\mathrm{C}_{\infty_{\mathrm{v}}}\right)$. For the K-capped models, the counterion is added to each end of the chain to maintain a symmetric environment and to neutralize the negative charge of the $\left[\mathrm{Cu}_{n}(\mathrm{CN})_{n+1}\right]^{-}$complex ions. ${ }^{29}$ The latter prevents underestimation of the electron binding energy known for anions within DFT, but may shift the excitation energies to shorter wavelengths due to the overall positive charge. Potassium was selected as the counterion because it is commonly used as a mineralizing agent for $\mathrm{CuCN}$.

The fully symmetric isomers of the odd K-capped $\mathrm{CuCN}$ chains $\left(\left\{\mathrm{K}_{2}\left[\mathrm{Cu}_{\mathrm{n}}(\mathrm{CN})_{\mathrm{n}+1}\right]\right\}^{+} ; \mathrm{n}=\right.$ $\left.1\left(\mathbf{1}^{\mathbf{K}}\right), 3,\left(\mathbf{3}^{\mathbf{K}}\right), 5\left(\mathbf{5}^{\mathbf{K}}\right), 7\left(\mathbf{7}^{\mathbf{K}}\right)\right)$ with the carbon end of all cyano groups oriented toward the center copper were optimized in using five xc functionals: SVWN, BLYP, BP86, HCTH/407 and mPW1PW91 (Table 1 (BLYP only) and Supplementary Table 1). The geometries of the analogous bare $\left[\mathrm{Cu}_{\mathrm{n}}(\mathrm{CN})_{\mathrm{n}+1}\right]^{-}$anions were calculated in the BLYP functional only (Table 1) and are generally similar to the K-capped cations. With each functional, the $\mathrm{Cu}-\mathrm{C}$ bond distances to the central copper are longer than those of the outer coppers by $\sim 0.02 \AA$ due to the symmetrical environment around the metal. The $\mathrm{Cu}-\mathrm{C}, \mathrm{Cu}-\mathrm{N}$ and $\mathrm{C}-\mathrm{N}$ distances for the inner copper centers are often identical within the chains with the exception of the mPW1PW91 model for which the distances for the terminal cyano are slightly longer. The local density approximation (SVWN) generally produces bond distances to the formally positive copper and potassium ions that are

0.03-0.06 $\AA$ shorter than those obtained by the other functionals. The $\mathrm{Cu}-\mathrm{C}$ and $\mathrm{Cu}-\mathrm{N}$ distances for BLYP, BP86, HCTH/407 and mPW1PW91 functionals are comparable to the experimental $\mathrm{Cu}-\mathrm{X}$ bond distances (HT $1.870,{ }^{5} \mathrm{LT} 1.82-1.87^{4} \AA$ ). The $\mathrm{C}-\mathrm{N}$ distances are longer than those in the linear HT phase (1.12) and comparable to the distances in the LT phase (1.145-1.178). In 
comparison to the BLYP results, the $\mathrm{C}-\mathrm{N}$ distances in the mPW1PW91 functional and the distances around the copper center for the BP86 functional are slightly shorter than the BLYP values.

The disorder in the X-ray structures of the $\mathrm{CuCN}$ network allows for no definitive pattern in the orientation of the alternating cyanide groups. The geometries of the unique isomers ${ }^{30}$ of the bare anionic and $\mathrm{K}$-capped $\left(\mathrm{Cu}(\mathrm{CN})_{2}\right)$ and $\left(\mathrm{Cu}_{3}(\mathrm{CN})_{4}\right)$ chains were calculated at the BLYP level for comparison to the fully symmetric isomers (Table 2). Isomers are labeled by the direction of the cyanide group within the chain (Chart 1): $\mathrm{R}$ for the $\mathrm{CN}$ orientation and $\mathrm{L}$ for the NC orientation. There are three unique isomers for the $\mathrm{n}=1$ chain $\left(\mathbf{1} \mathbf{R L} \equiv \mathbf{1}[\mathrm{N} \equiv \mathrm{C}-\mathrm{Cu}-\mathrm{C} \equiv \mathrm{N}]^{-}\right.$, $\mathbf{1}_{\mathbf{L R}}[\mathrm{C} \equiv \mathrm{N}-\mathrm{Cu}-\mathrm{N} \equiv \mathrm{C}]^{-}$and $\left.\mathbf{1}_{\mathbf{R R}}=\mathbf{1}_{\mathbf{L L}}[\mathrm{C} \equiv \mathrm{N}-\mathrm{Cu}-\mathrm{C} \equiv \mathrm{N}]^{-}\right)$. The symmetric isomer $\mathbf{1}^{\mathbf{K}}$ having the normal carbon linkage to the central copper is $\sim 20 \mathrm{kcal} / \mathrm{mol}$ lower in energy than $\mathbf{1}_{\mathbf{L R}} \mathbf{K}^{\mathbf{K}}$ for which nitrogen bonds to the metal (isocyanide). The $\mathrm{Cu}-\mathrm{N}$ distances in this isomer are shorter (1.835 $\AA$ ) and the terminal $\mathrm{N}-\mathrm{K}$ distances are longer $(2.815 \AA)$ than those of $\mathbf{1}^{\mathbf{K}}$. The isomer with asymmetric linkages, $\mathbf{1}_{\mathbf{R R}}{ }^{\mathbf{K}}$, lies $\sim 10 \mathrm{kcal} / \mathrm{mol}$ above $\mathbf{1}^{\mathbf{K}}$. In this case, the $\mathrm{Cu}-\mathrm{C}$ and $\mathrm{Cu}-\mathrm{N}$ distances (1.853 and $1.857 \AA$, respectively) are shorter than either of the symmetric isomers. Although these distances are similar, the $\mathrm{C}-\mathrm{K}$ distance is $\sim 0.15 \AA$ longer than $\mathrm{N}-\mathrm{K}(2.817$ versus $2.645 \AA$ ). The geometries and energies of the bare anion isomers of $\mathbf{1}$ are similar to those of the K-capped system (Table 2). Based upon the foregoing observations it can be reasoned that the higher energy of LR and RR isomers are due to the unfavorable coordination of terminal isocyanides.

Of the ten unique $\mathrm{n}=3$ isomers (Chart 1$)$, four are $\mathrm{D}_{\infty \mathrm{h}}\left(\mathbf{3}_{\mathbf{R R L L}} \equiv \mathbf{3}, \mathbf{3}_{\mathbf{L R L R}}, \mathbf{3}_{\mathbf{R L R L}}, \mathbf{3}_{\text {LLRR }}\right)$

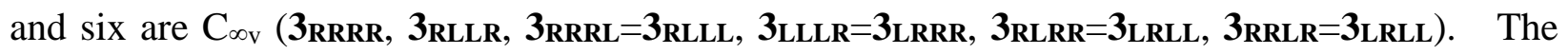
relative energies of each of these isomers calculated at the DFT(BLYP) level for both the bare and K-capped ions are listed in Table 2. The isomer with alternate $\mathrm{Cu}$ coordination spheres $\left(3_{\text {RLRL }}=[\mathrm{N} \equiv \mathrm{C}-\mathrm{Cu}-\mathrm{C} \equiv \mathrm{N}-\mathrm{Cu}-\mathrm{N} \equiv \mathrm{C}-\mathrm{Cu}-\mathrm{C} \equiv \mathrm{N}]^{-}\right)$is $\sim 1.5 \mathrm{kcal} / \mathrm{mol}$ less stable than 3 . Both of the symmetric isomers with terminal isocyanide linkages (3 $\mathbf{L R L R}, \mathbf{3}_{\text {LLRR) }}$ lie 21-23 kcal/mol above 3, with the alternating chain $\mathbf{2}_{\text {LRLR }}$ being $\sim 2 \mathrm{kcal} / \mathrm{mol}$ less stable than $\mathbf{2}_{\mathbf{L L R R}}$. With the exception of 3RRRL, the remaining isomers each have at least one terminal isocyanide linkage and, as a result, are destabilized by $\sim 10 \mathrm{kcal} / \mathrm{mol}$. The $\mathbf{3}_{\mathbf{R R R L}}$ isomer reverses the linkage of one of the central cyanides and is slightly more stable $(<0.1 \mathrm{kcal} / \mathrm{mol})$ than the fully symmetric isomer $\mathbf{3}$. 
Geometries were calculated for ten of the 36 unique $\left\{\mathrm{K}_{2}\left[\mathrm{Cu}_{5}(\mathrm{CN})_{6}\right]\right\}^{+}$isomers, those with normal cyanide linkages at the terminal positions, due to the higher relative energies obtained for the smaller model isomers containing terminal isocyanide linkages. Most of the $n=5$ isomers lie $1.7 \mathrm{kcal} / \mathrm{mol}$ higher in energy than the fully symmetric chain $\mathbf{5}$. The isomer with alternating symmetric $\mathrm{Cu}$ coordination, 5RLRLRL, is $3 \mathrm{kcal} / \mathrm{mol}$ above $\mathbf{5}$. The lowest energy isomers are those with asymmetric coordination for all but one copper ion which has $\mathrm{NC}-\mathrm{Cu}-\mathrm{CN}$ coordination: 5, 5RRRRrL, 5RRRRLL. The stability of these isomers, as well as that of $\mathbf{3}$ and $\mathbf{3}$ RRRL, demonstrate a preference for chains with minimal 'defects' in the orientation of the cyanides, a situation which is difficult to determine from the X-ray data since defects may appear at different sites in the chains, leading to disorder.

The geometries of the even-numbered bare anionic and $\mathrm{K}$-capped $\mathrm{CuCN}$ chains $\left[\mathrm{Cu}_{\mathrm{n}}(\mathrm{CN})_{\mathrm{n}+1}\right]^{-}(\mathrm{n}=2$ and 4) were optimized at the DFT(BLYP)/BSI for the isomers with terminal normal linkage of the cyanides only. The bond distances for the single isomer of the $n=2$ chain $\left(\mathbf{2} \equiv \mathbf{2}_{\mathbf{R L L}}=\mathbf{2} \mathbf{R R L}\right)$ and the four unique isomers of the $\mathrm{n}=4$ chain $\left(\mathbf{4}_{\equiv} \equiv \mathbf{4}_{\mathbf{R R R R L}}=\mathbf{4}_{\mathbf{R L L L L}}\right.$, $\mathbf{4}_{\mathbf{R R L R L}}=\mathbf{4}_{\mathrm{RLRLL}}, \mathbf{4}_{\mathrm{RRRLL}}=\mathbf{4}_{\mathrm{RRLLL}}, \mathbf{4}_{\mathrm{RLLRL}}=\mathbf{4}_{\mathrm{RLRRL}}$ ) are similar to those for the odd chains. As for the odd chains, there is a preference for asymmetric coordination spheres all of the copper centers but one. The isomers 4 and $\mathbf{4}_{\text {RRRLL }}$ are $1.5 \mathrm{kcal} / \mathrm{mol}$ below the two isomers having two coppers with normal cyanide linkages (Table 2).

Excitation spectra. The UV/Vis spectra of the fully symmetric bare and $\mathrm{K}$-capped $\left[\mathrm{Cu}_{\mathrm{n}}(\mathrm{CN})_{\mathrm{n}+1}\right]^{-}$ chains were simulated by TD-DFT using both pure (BLYP, BP86, HCTH/407 and SVWN) and hybrid (mPW1PW91) xc functionals. Analysis of the transitions shows that the dominant bands (oscillator strength > 0.1, Table 3 (BLYP only) and Supplementary Table 2) are the Laporteallowed transitions between MOs of $\pi$ symmetry (Fig 2). Other Laporte-allowed transitions ( $\sigma-\sigma$ and $\delta-\delta$ ) have oscillator strengths at least one order of magnitude lower than those of the $\pi-\pi$ transitions. For the $n=1$ chains, the pure xc functionals (BLYP, BP86, HCTH/407 and SVWN) produce a single high intensity band (230-240 nm) within the range of the calculation. This band is consistent with the observed $\lambda_{\max }$ for the $\mathrm{UV}$ spectrum of $\left[\mathrm{Cu}(\mathrm{CN})_{2}\right]^{-}$in solution $(234$ $\mathrm{nm}){ }^{31}$ The hybrid mPW1PW91 xc functional obtains no transitions with oscillator strengths above 0.1 for these chains, but produces a similar pattern to those of the pure functionals in $3^{\mathbf{K}}$ shifted to lower wavelengths by 30-50 nm (Supplementary Table 2). 
The single band for $\mathbf{1}$ and $\mathbf{1}^{\mathrm{K}}$ predominantly consists of contributions from transitions from the occupied $3 \pi_{\mathrm{g}} \mathrm{MO}(\mathrm{HOMO}-2)$ to the empty $4 \pi_{\mathrm{u}} \mathrm{MO}\left(\mathbf{1}, \mathrm{LUMO} ; \mathbf{1}^{\mathrm{K}}, \mathrm{LUMO}+2\right)$. These are the highest occupied and lowest unoccupied $\pi$-type MOs. The band for $\mathbf{1}^{\mathbf{K}}$ also includes lesser contributions from transitions from $3 \pi_{\mathrm{g}}$ to $5 \pi_{\mathrm{u}}(\mathrm{LUMO}+4)$ and $7 \sigma_{\mathrm{u}}(\mathrm{HOMO}-3)$ to the $10 \sigma_{\mathrm{g}}$ MO (LUMO+1). This band has previously been assigned as MLCT, ${ }^{32}$ but the present calculations show a significant amount of metal and cyano character in both MOs (Fig 2). The character of these MOs may explain why the excitation bands derived from the hybrid mPW1PW91 functional are consistently lower that those of the pure functionals. Hybrid functionals generally outperform pure functionals because CT often occurs between MOs that are localized on different parts of the molecule, ${ }^{11}$ as is often true for MLCT bands in $\mathrm{d}^{6} \mathrm{TM}$ complexes. ${ }^{17}$ In each of the model $\mathrm{CuCN}$ chains, the donor and acceptor MOs are delocalized over the length of the chains such that extended polyenes and polyynes are a better analogy. Within these species, pure functionals often give similar or better results than hybrid functionals so long as the excitations are not CT in nature. For example, the BLYP functional obtains better overall results in comparison to B3LYP for the Q bands of chlorophyll and the $\mathrm{S}$ bands of zeaxanthin, a xanthophyll. ${ }^{13 b}$ In addition, the error for longest wavelength transition of $\mathrm{H}-\mathrm{C} \equiv \mathrm{C}-\mathrm{C} \equiv \mathrm{C}-\mathrm{H}$ calculated using BLYP/TZVP is only $0.1 \mathrm{eV}$ compared to $0.45 \mathrm{eV}$ at B3LYP. ${ }^{33}$ The hybrid functional significantly overestimates the transition energies for polyynes as in the case of our CuCN model chains. BLYP also produces better vertical singlet-triplet gaps for polyenes than B3LYP, underestimating these by $\sim 0.2 \mathrm{eV} .^{34}$ The BP86 functional performs as well as B3LYP for the long-axis polarized band of a series of condensed acenes for which transitions are between bonding MOs. However, the predicted excitation energies for the shortaxis polarized band diverge due to the ionic nature of the excited state. ${ }^{14}$

Increasing the length of the chain adds one or more excitation bands at longer wavelength (Table 3). The lowest energy transition for the $n=2,3,4,5$ and 7 chains are the excitations from the highest occupied to the lowest unoccupied $\pi$-type MO. For example, the $314 \mathrm{~nm}$ band for $\mathbf{3}$ and the $276 \mathrm{~nm}$ band for $\mathbf{3}^{\mathbf{K}}$ correspond to the excitation from $6 \pi_{\mathrm{g}}(\mathrm{HOMO}-3)$ to $7 \pi_{\mathrm{u}}(\mathbf{3}$, LUMO; $3^{\mathrm{K}}$, LUMO+2) MO. Likewise, the longest wavelength bands in the $\mathrm{n}=5$ and $\mathrm{n}=7$ chains are $9 \pi_{\mathrm{g}}(\mathrm{HOMO}-4)$ to $10 \pi_{\mathrm{u}}\left(\mathbf{5}, \mathrm{LUMO} ; \mathbf{5}^{\mathrm{K}}, \mathrm{LUMO}+2\right)$ and $12 \pi_{\mathrm{g}}(\mathrm{HOMO}-4)$ to $13 \pi_{\mathrm{u}}(\mathbf{7}$, LUMO; $\left.7^{\mathbf{K}}, \mathrm{LUMO}+2\right)$, respectively. For the even chains, for which inversion symmetry is lost, the longest wavelength bands are $9 \pi$ (HOMO-2) to $10 \pi$ (LUMO+2) for $2^{\mathrm{K}}$ and $15 \pi(\mathrm{HOMO}-3)$ 
to $16 \pi(\mathrm{LUMO}+2)$ for $\mathbf{4}^{\mathrm{K}}$. In each of these cases, the donor MO has antibonding character between the $\mathrm{Cu} 3 \mathrm{~d}_{\pi}$ AOs and the $\mathrm{CN} \pi$ bonds and the acceptor MO has bonding character between the $\mathrm{Cu} 4 \mathrm{p}$ AOs and the $\mathrm{CN} \pi^{*}$ fragments. Additional bands arise from transitions to/from $\pi$ MOs lying lower in energy than these occupied MOs or higher than these unoccupied MOs. For example, for $\mathbf{3}^{\mathbf{K}}$ the second intense line $(240.6 \mathrm{~nm})$ results from excitation from $6 \pi_{\mathrm{u}}$ (HOMO-6) to $7 \pi_{\mathrm{g}}(\mathrm{LUMO}+3)$ and the third $(238.6 \mathrm{~nm})$ from the $6 \pi_{\mathrm{g}}(\mathrm{HOMO}-3)$ to $8 \pi_{\mathrm{u}}$ (LUMO+4) transition. The lower energy occupied MOs are generally antibonding between the $\mathrm{Cu} 3 \mathrm{~d}_{\pi}$ AOs and the $\mathrm{CN} \pi$ fragments, although some low energy MOs such as $5 \pi_{\mathrm{g}}$ for $5^{\mathrm{K}}$ (Fig 2) show bonding interaction between copper and carbon. The higher virtual MOs are generally bonding combinations of the $\mathrm{Cu} 4 \mathrm{p}$ AOs and $\mathrm{CN} \pi^{*}$ and include contributions from the $\mathrm{K} 4 \mathrm{p}$ MOs as an artifact of the capped models.

From these data, we can see that as the chain length becomes longer, the longest wavelength transition for the K-capped chains approaches an asymptotic value of $300 \mathrm{~nm}$, short of the experimental $\lambda_{\max }$ by $\sim 40 \mathrm{~nm}$. The intensity of the line, based upon the oscillator strength, also increases as the wavelength increases, mirroring the extinction pattern in the experimental spectrum. For example, the transition lines for $\mathbf{7}^{\mathbf{K}}$ are shown in Fig 3 with their intensities as predicted by the oscillator strength. The long wavelength bands are twice as intense as the short wavelength bands, giving a good approximation of the stair-step shape seen in the experimental spectrum (compare Fig 11A in ref 3c). The approach of the calculated spectra to an asymptotic value is expected by analogy to the extended $\pi$ systems of polyynes. ${ }^{16}$ However, the limiting value is approached more quickly for the $\mathrm{K}$-capped $\mathrm{CuCN}$ chains than for polyyne oligomers, for which a limit has not been reached at 24 carbon atoms. For the bare-anionic chains, additional bands are also obtained as the chain length increases, but these do not approach an asymptotic value for the model chain lengths calculated. For 7, the long wavelength $\pi-\pi$ transitions also decrease in intensity from a maximum at the $278.8 \mathrm{~nm}$ band (Table 3). The transition between the highest occupied and lowest unoccupied $\pi$ MOs is calculated to occur at $\sim 460 \mathrm{~nm}$ with an oscillator strength of 0.03 . Of the two model types, we believe the K-capped provide the better overall representation of solid-state $\mathrm{CuCN}$ because the pattern in the line intensities and the convergence to a limiting wavelength are consistent with the excitation spectrum in Fig $11 \mathrm{~A}$ in reference 3c. The fact that the limiting wavelength is found at energies higher than those from experiment can be attributed to the overall positive charge of the chain models. The errors in 
these gas-phase models may also be attributed to the lack of intermolecular interactions necessarily present in the solid state.

Note that the TD-DFT calculations do not predict a significant contribution to the excitation spectrum from the HOMO-LUMO transition. The HOMOs are metal-centered MOs of $\sigma$ or $\sigma_{\mathrm{g}}$ symmetry consisting of the in-phase combination of $\mathrm{sd}_{\mathrm{z}} 2$ hybrid AOs. For the bare anions, transitions from these MOs to the $\pi$-type LUMOs are symmetry-forbidden and the oscillator strength of the HOMO-LUMO transition is zero. The LUMOs for the K-capped chains are the asymmetric combination of potassium $4 \mathrm{~s}$ AOs $\left(\sigma_{u}\right)$ such that the HOMO/LUMO transition is both symmetry-allowed $(\sigma \rightarrow \sigma)$ and Laporte-allowed $(\mathrm{g} \rightarrow \mathrm{u})$, but TD-DFT assigns small oscillator strengths to these transitions. For example, the HOMO-LUMO transition for $\mathbf{3}^{\mathbf{K}}$ has an oscillator strength two orders of magnitude lower than the highest energy $\pi-\pi$ transition. The LUMO and LUMO+1, the symmetric K 4s combination, as well as the transitions to these MOs, are artifacts of the K-capped model.

Luminescence excitation in $\mathrm{Cu}(\mathrm{I})$ has variously been described as arising from $\mathrm{MC}$ or MLCT transitions. Let us consider how these descriptions harmonize with the relevant MOs described above. As shown in Fig 2, copper components of the highest occupied $\pi$ MOs are largely $3 d_{x z} / 3 d_{y z}$, while those of cyanide are essentially $\pi$-bonding. The lowest unoccupied $\pi$ MOs may be described as $\mathrm{Cu} 4 \mathrm{p}_{\mathrm{x}} / 4 \mathrm{p}_{\mathrm{y}}$ and cyano $\pi^{*}$. Therefore, the transition between these orbitals can be regarded as MC $(3 \mathrm{~d} \rightarrow 4 \mathrm{p})$ or MLCT $\left(3 \mathrm{~d} \rightarrow \pi_{\mathrm{CN}} *\right)$. However, it can also be seen as LMCT $\left(\pi_{\mathrm{CN}} \rightarrow 4 \mathrm{p}\right)$ or even as ligand centered $\left(\pi_{\mathrm{CN}} \rightarrow \pi_{\mathrm{CN}^{*}}\right)$, although this latter description is probably the least reasonable. Nevertheless, it is probably most useful to regard the excitation in $\mathrm{CuCN}$ as involving a combination of $\pi$-symmetry MC and CT components or simply as an intrachain $\pi-\pi$ transition. Since electrons are excited from occupied MOs with antibonding character between the $d_{\pi} \mathrm{Cu}$ AOs and the $\pi \mathrm{CN}$ fragments to unoccupied MOs with bonding character between the $\mathrm{Cu}$ p AOs and $\pi^{*} \mathrm{CN}$ fragments, we may expect to find $\mathrm{Cu}-$ cyano bonding strengthened upon excitation, while $\mathrm{C} \equiv \mathrm{N}$ bonding would be weakened.

Emission spectra. The emission spectrum of $\mathrm{CuCN}$ is assumed to arise from transition from the lowest excited state triplet to the ground state. Lifetime studies of soluble $\mathrm{Cu}(\mathrm{I})$ cyano species have suggested that emission is usually a phosphorescence phenomenon. ${ }^{8,31,32}$ We assume that this triplet forms through intersystem crossing from the photoexcited singlet states and do not 
model this process explicitly. For the K-capped chains $\mathbf{1}^{\mathbf{K}}, \mathbf{3}^{\mathrm{K}}$, and $\mathbf{5}^{\mathrm{K}}$, adiabatic $\mathrm{S}-\mathrm{T}$ gaps were determined using the optimized geometries (DFT/BLYP) of the lowest triplet state in the $\mathrm{D}_{\infty \mathrm{h}}$ and $\mathrm{C}_{2 \mathrm{v}}$ point groups. Vertical $\mathrm{S}-\mathrm{T}$ gaps calculated by a TD-DFT calculation generating the triplet excited states are generally similar to the linear adiabatic $\mathrm{S}_{0}-\mathrm{T}$ gaps.

For $1^{\mathrm{K}}$, the lowest energy linear triplet lies $4.83 \mathrm{eV}$ above the ground state and is energetically equivalent to emission of a $257 \mathrm{~nm}$ photon. The unpaired electrons occupy the $3 \pi_{\mathrm{g}}$ (3e) and $4 \pi_{\mathrm{u}}$ (1e) MOs, linking this excited state to the lowest energy transition $\left(232.2 \mathrm{~nm}, 4 \pi_{\mathrm{u}}\right.$ $\leftarrow 3 \pi_{\mathrm{g}}$ ) calculated by the TD-DFT calculation. Because the partially occupied $4 \pi_{\mathrm{u}} \mathrm{MO}$ has $\mathrm{Cu}-\mathrm{C}$ bonding and $\mathrm{C}-\mathrm{N}$ antibonding character, the central $\mathrm{Cu}-\mathrm{C}$ and $\mathrm{C}-\mathrm{N}$ distances are slightly shorter $(1.868 \AA)$ and longer $(1.187 \AA)$, respectively, than the ground state singlet values. Vibrational analysis shows that this species has a single imaginary frequency which characterizes it as a transition state for bending of the linear chain. Based upon these results, the $\mathrm{C}_{2 \mathrm{v}}$ geometries of the chains were determined under the assumption that upon excitation of an electron to a degenerate $\mathrm{MO}$, the structure will relax via some distortion. The optimized structure of the lowest $\mathrm{C}_{2 \mathrm{v}}$ triplet state $\left(\mathrm{b}_{2}\right)$ shows that distortions are localized around the central copper center where the chain is bent by $97.8^{\circ}$ and the $\mathrm{Cu}-\mathrm{C}$ distances are elongated by $0.14 \AA$ relative to $\mathbf{1}$. The $\mathrm{C}-\mathrm{N}$ and $\mathrm{N}-\mathrm{K}$ bond distances are slightly longer than in the ground state. Significant distortions are also found in the optimized structure of the triplet state of the $\left[\mathrm{Au}(\mathrm{SCN})_{2}\right]^{-}$dimer assumed to contribute to the luminescence properties of $\mathrm{K}\left[\mathrm{Au}(\mathrm{SCN})_{2}\right] .{ }^{35}$

The bending of the chain is consistent with a distortion to remove the degeneracies of the partially occupied $3 \pi_{\mathrm{g}}$ and $4 \pi_{\mathrm{u}}$ MOs which decompose as $\mathrm{b}_{2}+\mathrm{a}_{2}$ and $\mathrm{a}_{1}+\mathrm{b}_{1}$ in $\mathrm{C}_{2 \mathrm{v}}$ symmetry (Fig 4). The relaxation of the triplet geometry reduces the energy gap to the ground state by $\sim 1$ $\mathrm{eV}$ and shifts the wavelength of the predicted emission to $330 \mathrm{~nm}$. The bent structure also concentrates the spin density on the central copper center (1.368), with some spin density found on the carbons of the central cyanide groups (0.271). The spin for the linear triplets is also predominately found on the central copper atom (1.307); however greater spin distribution is seen throughout the chain, especially through the entire central cyanide ligands $(\mathrm{C}: 0.153, \mathrm{~N}$ : 0.183). Both the linear and bent structures are well-represented by triplet densities with very little spin contamination $\left(S^{2}=2.002\right)$.

The triplet states for $3^{\mathbf{K}}$ and $\mathbf{5}^{\mathbf{K}}$ leads to similar features in the optimized structures (Fig 5), with the exception that the linear triplets are minima on their respective potential energy 
surfaces. The linear $\mathrm{S}_{0}-\mathrm{T}$ gaps shift to longer wavelengths due to the smaller band gap observed for longer chains. The bent $\mathrm{C}_{2 \mathrm{v}} \mathrm{S}_{0}-\mathrm{T}$ gaps are found at slightly higher energies relative to the ground state. The bent triplet was also determined for the lowest energy $n=3$ chain, $\mathbf{3}_{\mathbf{R R R L}}{ }^{\mathbf{K}}$. The optimized structure of the ${ }^{3} \mathrm{~A}^{\prime}$ state features a bend in the chain at a terminal copper with little distortion in the rest of the chain. The $\mathrm{S}_{0}-\mathrm{T}$ gap for this structure is slightly smaller than that of $\mathbf{3}^{\mathbf{K}}(329.6 \mathrm{~nm})$. In both chains, the overall length of the chain is reduced in the $\mathrm{C}_{2 \mathrm{v}}$ triplet by $1.5 \AA$, and the bend in the chain results in a significant displacement of the central copper center from its position in the linear chain as defined by the positions of the potassium centers (see Fig 5).

The apparent bending of the triplet excited state is relevant to what is known about the photoexcitation of $\left[\mathrm{Cu}(\mathrm{CN})_{2}\right]^{-}$in solution. Horváth and Stevenson have both noted the tendency of $\left[\mathrm{Cu}(\mathrm{CN})_{2}\right]^{-*}$ to form exciplexes (e.g. with halide or amine ligands) or excimers in solution. ${ }^{8,31,32}$ It may well be that the bending of the excited state triplet lies behind exciplex or excimer formation. Such bending would open up a coordination site, easing formation of an additional metal covalent interaction with incoming nucleophile. In the case of the solutionphase excimers, this nucleophile would be another $\left[\mathrm{Cu}(\mathrm{CN})_{2}\right]^{-}$anion which could form a bridge though the cyano group, however, cuprophilic $\mathrm{Cu} \cdots \mathrm{Cu}$ interaction cannot be ruled out.

Although the $\mathrm{S}_{0}-\mathrm{T}$ gaps for the model chains are similar to the emission wavelength of $\mathrm{CuCN}$, comparisons to solid-state $\mathrm{CuCN}$ are more difficult due to concerns over the flexibility of the chains, the available space in the crystalline lattice and interchain interactions. Crystal structures of $\mathrm{CuCN}-\mathrm{L}$ networks suggest that bending in the extended chains can be facile. For example independent $\mathrm{CuCN}$ chains threaded through $\mathrm{CuCN}$-diamine networks show cyano- $\mathrm{Cu}$ cyano bond angles ranging from nearly $180^{\circ}$ to less than $150^{\circ} .3 \mathrm{~b}, 3 \mathrm{c}, 11 \mathrm{e}, 11 \mathrm{f}, 11 \mathrm{j}$ No doubt these angles are affected by packing effects, but they clearly reveal significant flexibility in $\mathrm{CuCN}$ chain bond angles. In addition, as-yet-unpublished results in our lab show that $\mathrm{CuCN}$ spontaneously absorbs liquid- or vapor-phase amines at room temperature to form $\mathrm{CuCN}-\mathrm{L}$ phases on the surface of the solid. The known CuCN-L phases can be recognized via X-ray diffraction. ${ }^{7}$ These phases show significant bending of the cyano-Cu-cyano angle due to formation of 3- and occasionally 4coordinate $\mathrm{Cu}$. Therefore, it appears that $\mathrm{CuCN}$ bending can indeed occur at room temperature in the solid state. However, insufficient space may be available within the crystal lattice to allow for the large distortions obtained for the bent triplet structures, but, in the solid state, distortions 
may not be as significant due to anchoring of the ends of the chain in the lattice. These restrictions in the movement of the chain may limit the bending to a single $\mathrm{Cu}(\mathrm{CN})_{2}$ unit. A reduction in the magnitude of the distortion necessarily reduces the $\mathrm{S}_{0}$ - $\mathrm{T}$ gap and shifts the emission to longer wavelengths. Finally, relaxation of the triplet through some inter-chain interaction similar to excimer formation in solution phase is also a possibility in the solid state. However, as the copper centers are not always aligned well for $\mathrm{Cu} \cdots \mathrm{Cu}$ interactions, inter-chain interactions may be more likely to take the form of $\mu_{3}$-cyano bridging of copper centers.

Therefore, the role of the bent excited state triplet is speculative pending further experimentation. Nevertheless, data for $\mathrm{CuCN}-\mathrm{L}$ networks may provide circumstantial support for the DFT results. We have noted that three-coordinate copper centers in CuCN-L complexes luminesce at longer wavelengths than those of $\mathrm{CuCN}^{3 \mathrm{c}}$ It may be theorized that the lower energy emission in $\mathrm{CuCN}-\mathrm{L}$ is also the result of lower site symmetry at the $\mathrm{Cu}(\mathrm{I})$ center. Since the three-coordinate copper centers in $\mathrm{CuCN}-\mathrm{L}$ are already bent (and therefore have lower local symmetry), no reorganizational energy is required for emissive relaxation. We have observed in some networks containing both 2-coordinate and 3-coordinate $\mathrm{Cu}$ centers that the $\mathrm{HE}$ band breaks into separate components at low temperature. ${ }^{3 c}$ Moreover, the higher energy feature in the $\mathrm{HE}$ band matches the emission energy of $\mathrm{CuCN}$ itself very closely. It follows that the observation of distinct HE and LE emission bands may be the result of multiple energetically accessible triplet states. Multiple states would arise through additional lower symmetry states in structurally complex $\mathrm{CuCN}-\mathrm{L}$ networks, wherein copper sites are no longer symmetrically or energetically equivalent.

\section{Conclusions}

Although there have been many reports of photoluminescent behavior in solid $\mathrm{Cu}(\mathrm{I})$ compounds, ${ }^{9}$ there have been relatively few involving CuCN-based materials. ${ }^{3,36}$ The preceding DFT study addresses a number of questions about the properties of the parent salt $\mathrm{CuCN}$ important to the understanding and design of $\mathrm{CuCN}$-based MONs. As we move from $\mathrm{CuCN}$ to $\mathrm{CuCN}-\mathrm{L}$ networks two generalizations stand out: (1) although excitation energy is essentially unchanged, $\mathrm{CuCN}-\mathrm{L}$ emits at lower energy than does $\mathrm{CuCN}$, and (2) $\mathrm{CuCN}-\mathrm{L}$ materials often show distinct high and low energy emission peaks (HE and LE). These HE and LE emission bands have been variously ascribed to MLCT and MC excitations. In contrast, our TD-DFT 
studies on isolated model chains suggest that the excitation spectrum appears to arise from intrastrand $\pi-\pi$ transitions resulting from excitations from occupied to unoccupied $\pi$-type MOs. Given the similarity in experimental excitation spectra between $\mathrm{CuCN}$ and $\mathrm{CuCN}-\mathrm{L}$, it appears that the $\mathrm{CuCN}$ excitation mechanism is not substantially altered in $\mathrm{CuCN}-\mathrm{L}$.

Luminescence emission is a more complicated matter. The behavior of $\mathrm{CuCN}$ and $\mathrm{CuCN}$ $\mathrm{L}$ are quite distinct. The present computational results suggest that a bent triplet state is responsible for the relatively high energy $\mathrm{CuCN}$ emission. This is an interesting conclusion since it suggests the formation of a distinct locus for emission behavior. Additional bonding at this bent copper site, leading to the exciplex and excimer formation previously noted in $\left[\mathrm{Cu}(\mathrm{CN})_{2}\right]^{-}$, would thus be facilitated. Moreover, under this scenario the lower energy luminescence emission noted in lower symmetry three-coordinate $\mathrm{CuCN}$ centers could be due to the lack of reorganizational energy associated with triplet formation.

\section{Acknowledgments}

Grateful acknowledgement is made by R.D.P. to the donors of the American Chemical Society Petroleum Research Fund (44891-B3). We also acknowledge a Howard Hughes Medical Institute grant through the Undergraduate Biological Sciences Education Program to the College of William and Mary.

Supporting Information Available: Cartesian coordinates of the bent triplet structures and tables of bond distances and TD-DFT transition wavelengths at the BLYP/BSII, SVWN, BP86, HCTH/407 and mPW1PW91 levels. This material is available free of charge via the Internet at http://pubs.acs.org. 


\section{Chart 1}

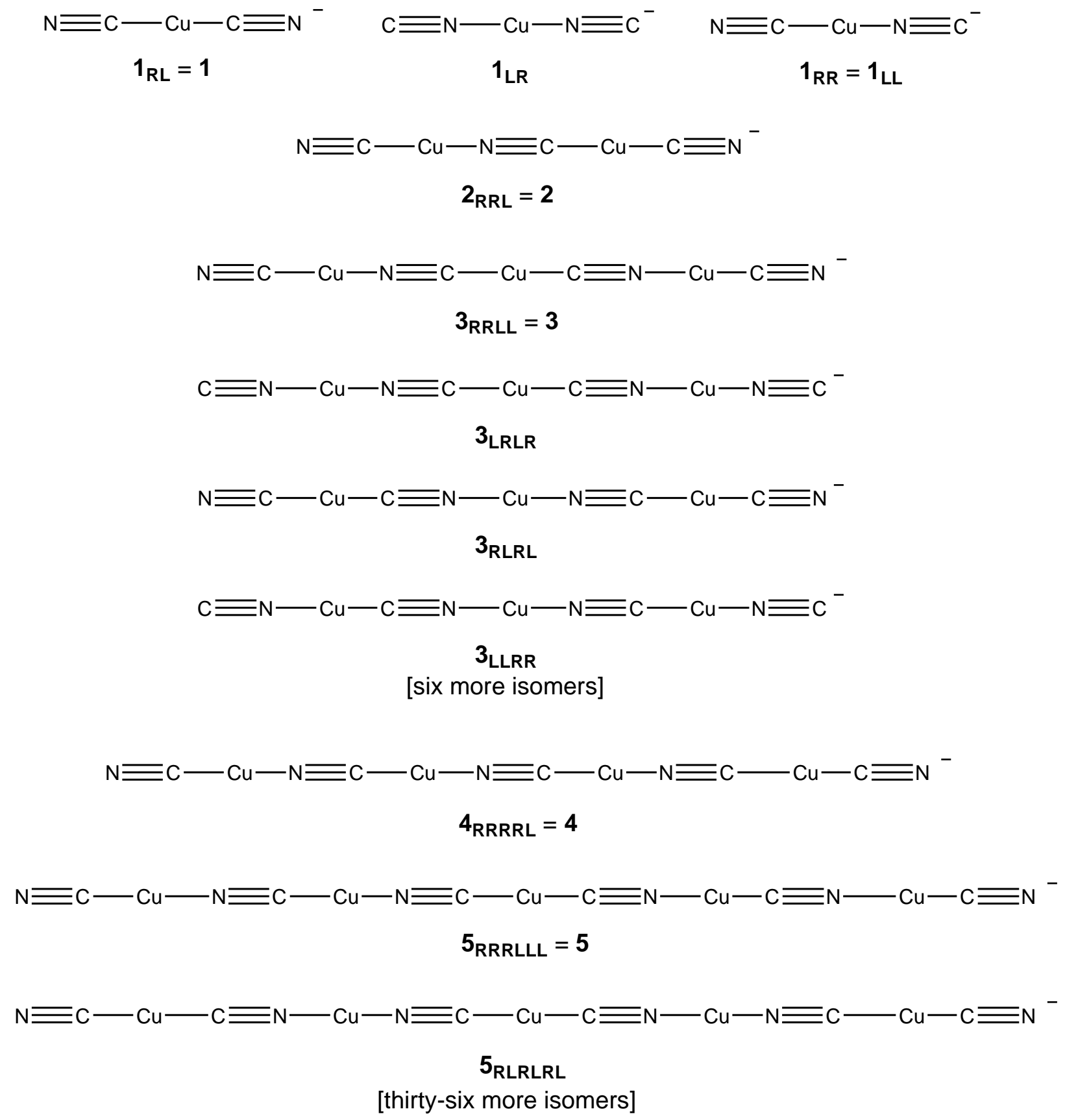



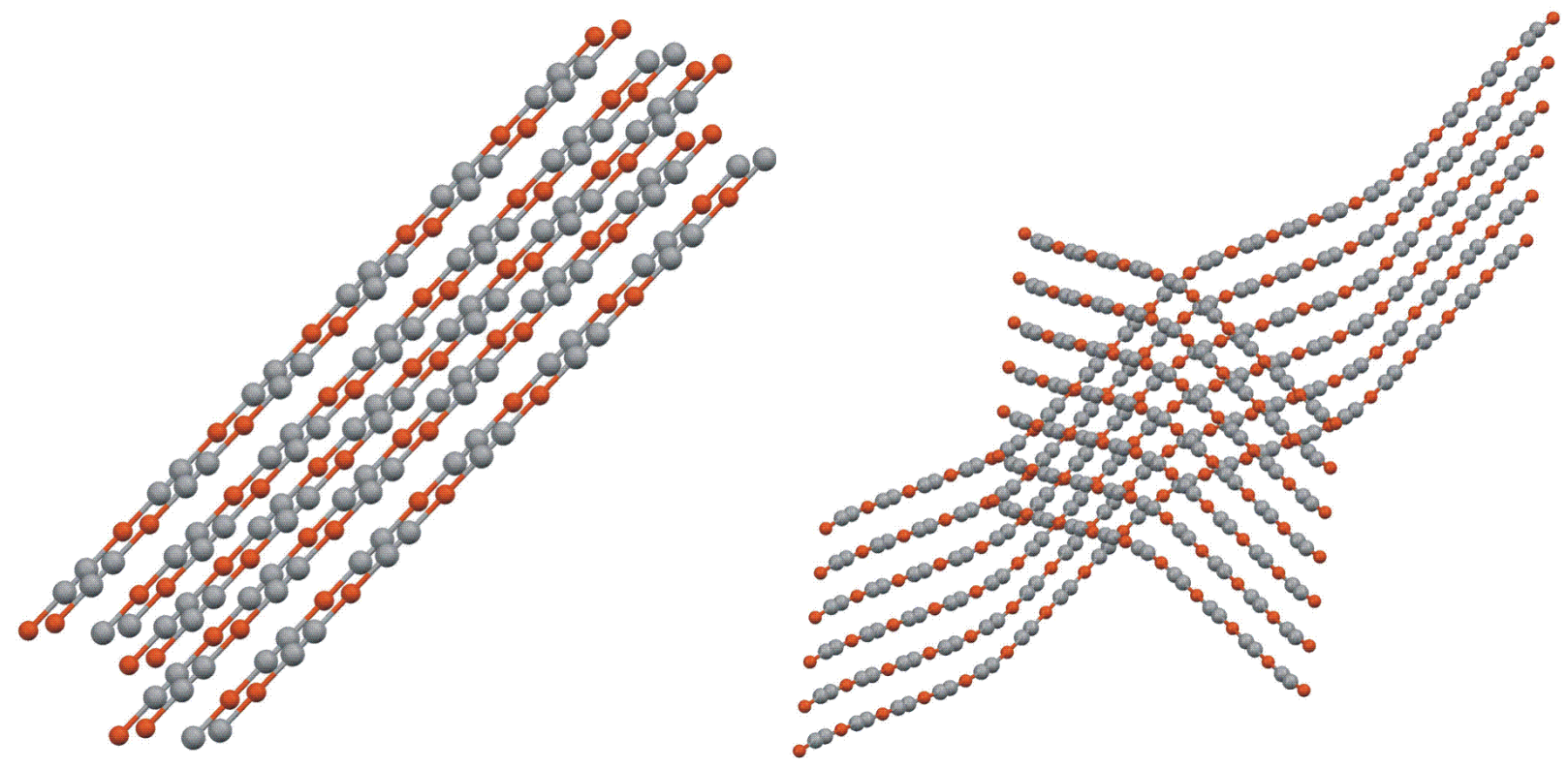

Figure 1. (A) High-temperature phase of $\mathrm{CuCN}$ X-ray structure. ${ }^{4}$ (B) Low-temperature phase of $\mathrm{CuCN}$ X-ray structure. ${ }^{5}$ (Ball and stick X-ray representations. $\mathrm{Cu}$ atoms orange, disordered $\mathrm{C} / \mathrm{N}$ atoms grey.) 

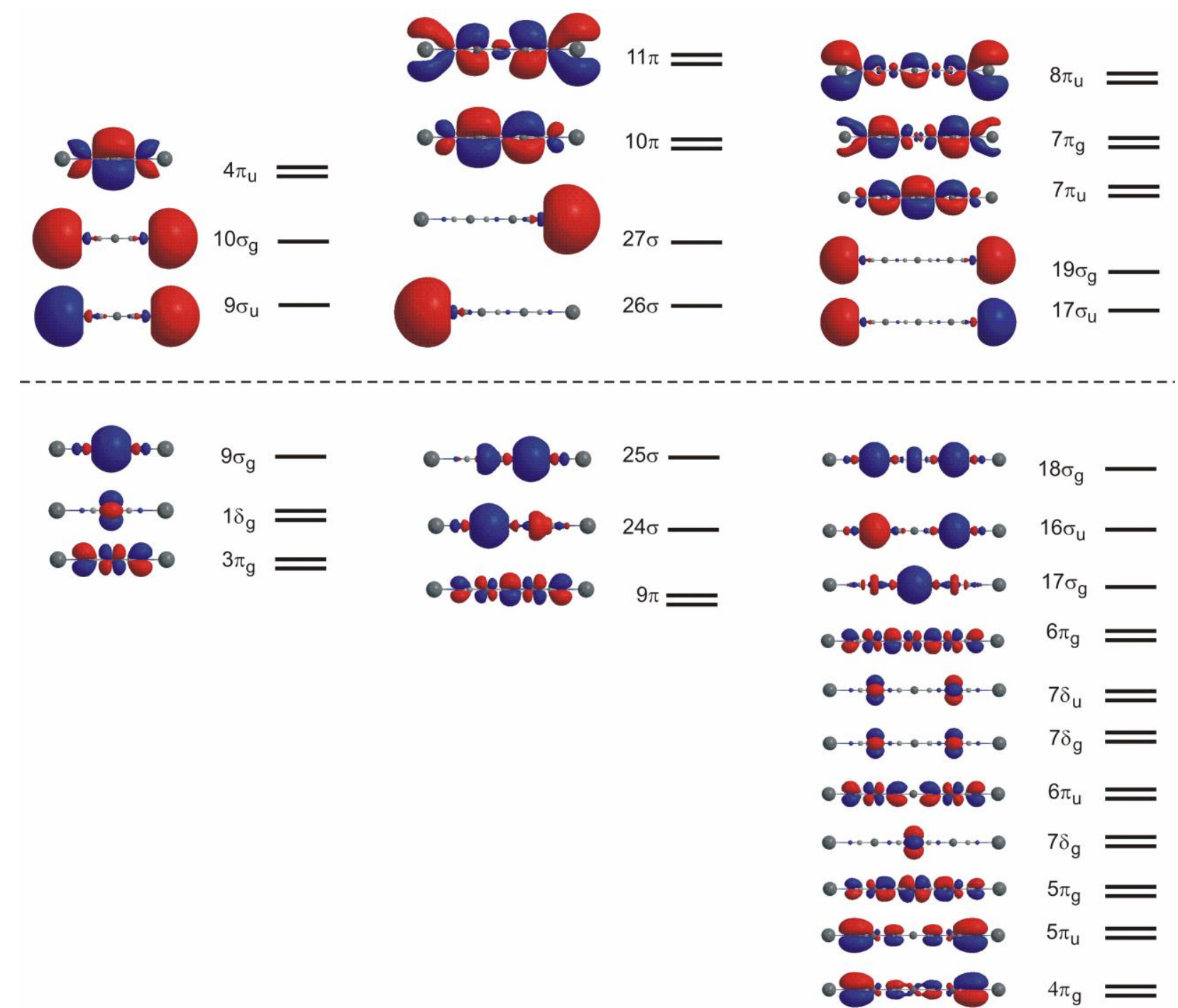

Figure 2. MO diagram for $\mathbf{1}^{\mathbf{K}}, \mathbf{2}^{\mathbf{K}}$ and $\mathbf{3}^{\mathrm{K}}$. The HOMO and HOMO+1 are artifacts of the K-capped chains and do not occur in the bare anionic chains. 


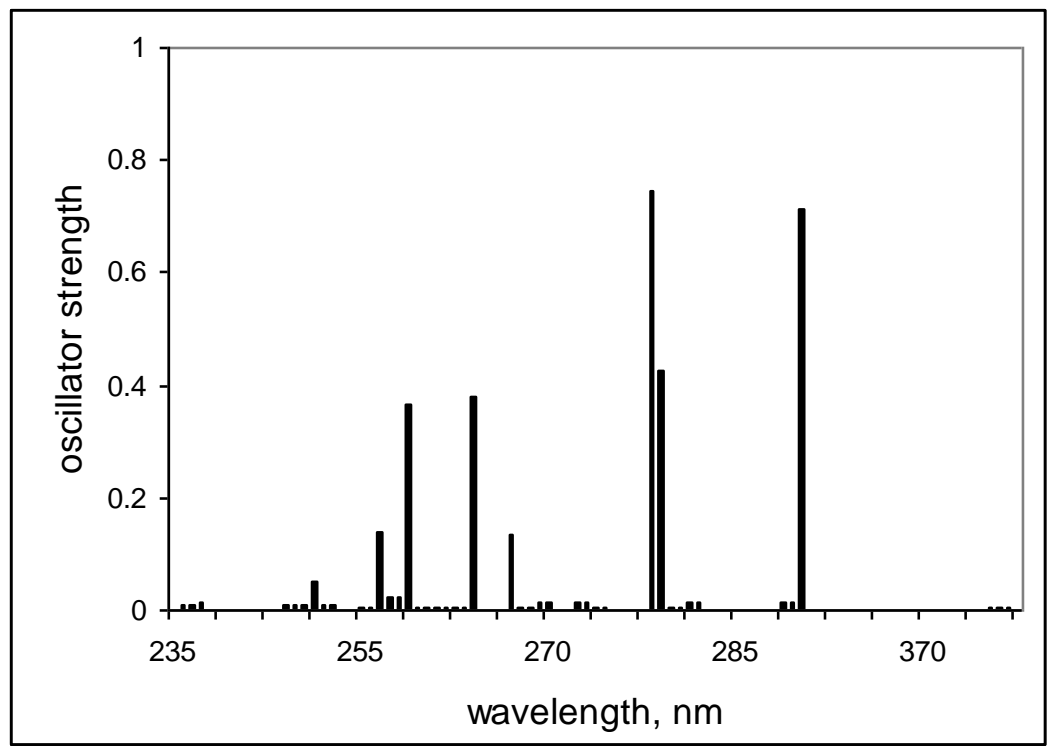

Figure 3. TD-DFT(BLYP) transition energies and oscillator strengths for $7^{\mathrm{K}}$.
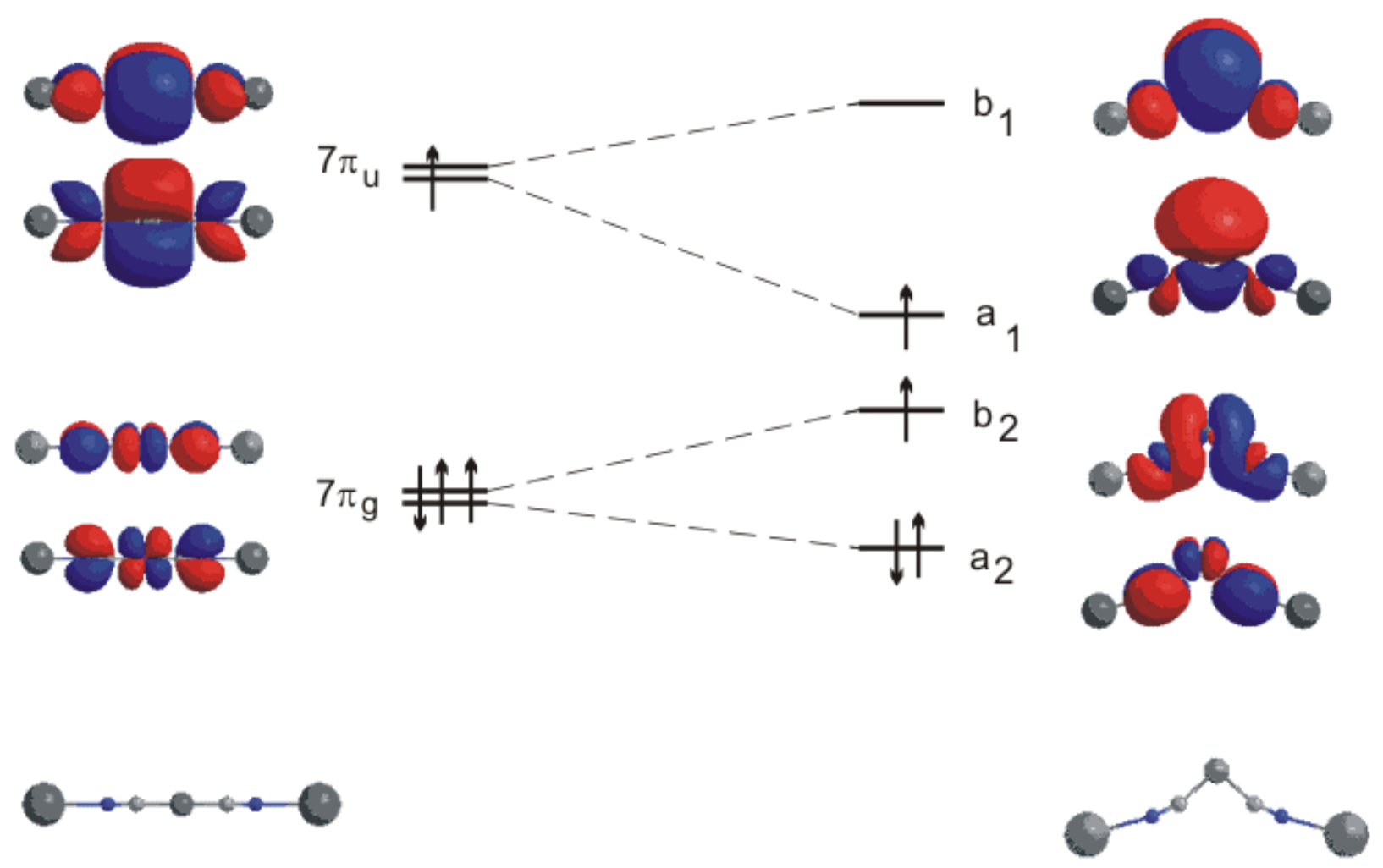

Figure 4. Walsh diagram of the distortion of the $\pi$ MOs of the triplet state of $\mathbf{1}^{\mathrm{K}}$ in $\mathrm{C}_{2 \mathrm{v}}$ symmetry. 

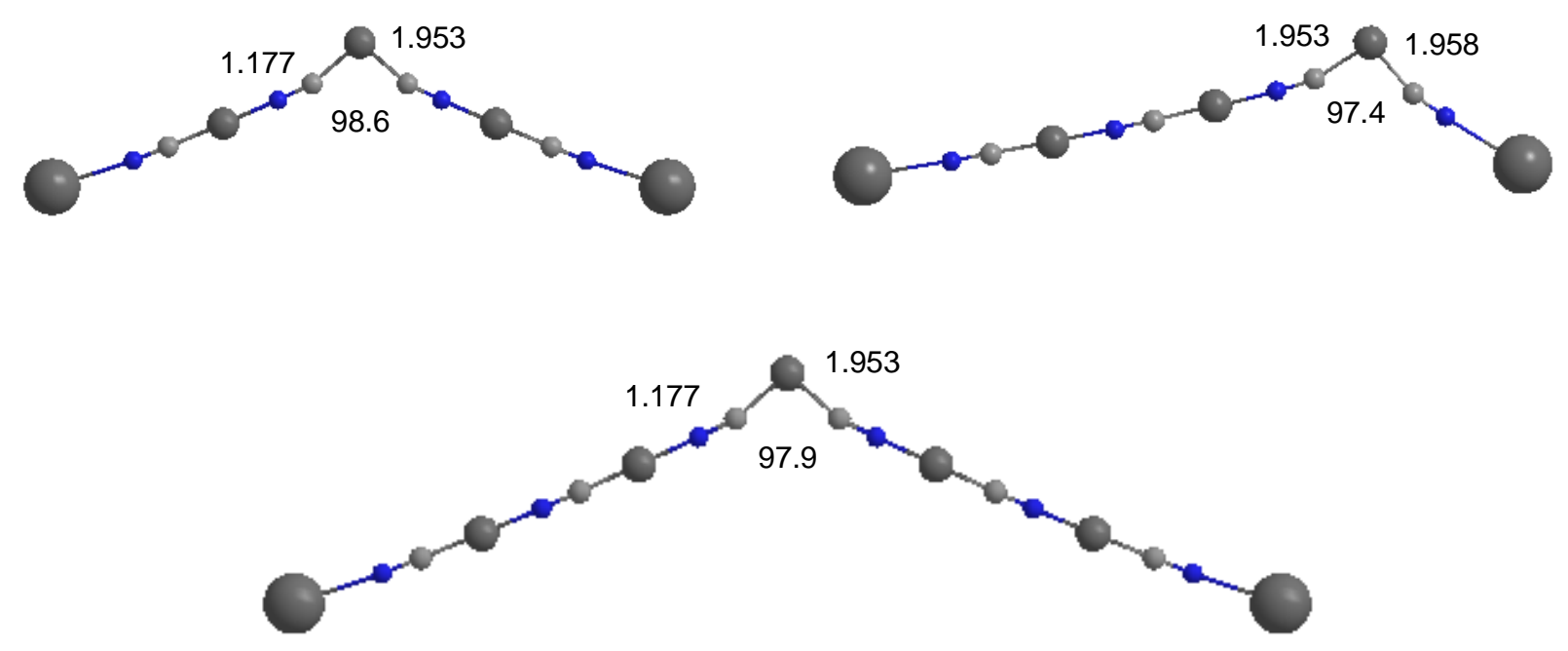

Figure 5. Structures of the bent triplet geometries of $\mathbf{3}^{\mathbf{K}}, \mathbf{3}_{\mathbf{R R R L}}{ }^{\mathbf{K}}$, and $\mathbf{5}^{\mathbf{K}}$ optimized at the unrestricted DFT/BLYP level. 
Table 1. Bond distances $(\AA)$ for the fully symmetric isomers of the bare and $\mathrm{K}$-capped chains $\left[\mathrm{Cu}_{\mathrm{n}}(\mathrm{CN})_{\mathrm{n}+1}\right]^{-}(\mathrm{n}=1,3,5,7)$ at the DFT(BLYP) level.

\begin{tabular}{llllllllllllll}
\hline & $\mathbf{1}$ & $\mathrm{Cu}-\mathrm{C}$ & $\mathrm{C}-\mathrm{N}$ & $\mathrm{N}-\mathrm{K}$ & & & & & & & & \\
\hline $\mathbf{1}$ & anion & 1.885 & 1.177 & & & & & & & & \\
& K-capped & 1.878 & 1.174 & 2.648 & & & & & & & \\
\hline & & $\mathrm{Cu}-\mathrm{C}$ & $\mathrm{C}-\mathrm{N}$ & $\mathrm{N}-\mathrm{Cu}$ & $\mathrm{Cu}-\mathrm{C}$ & $\mathrm{C}-\mathrm{N}$ & $\mathrm{N}-\mathrm{K}$ & & & & \\
\hline $\mathbf{3}$ & anion & 1.875 & 1.174 & 1.860 & 1.857 & 1.175 & & & & & \\
& K-capped & 1.875 & 1.173 & 1.856 & 1.853 & 1.174 & 2.642 & & & & & \\
\hline & & $\mathrm{Cu}-\mathrm{C}$ & $\mathrm{C}-\mathrm{N}$ & $\mathrm{N}-\mathrm{Cu}$ & $\mathrm{Cu}-\mathrm{C}$ & $\mathrm{C}-\mathrm{N}$ & $\mathrm{N}-\mathrm{Cu}$ & $\mathrm{Cu}-\mathrm{C}$ & $\mathrm{C}-\mathrm{N}$ & $\mathrm{N}-\mathrm{K}$ & & \\
\hline $\mathbf{5}$ & anion & 1.874 & 1.173 & 1.857 & 1.850 & 1.173 & 1.860 & 1.856 & 1.174 & & & \\
& K-capped & 1.874 & 1.173 & 1.855 & 1.848 & 1.173 & 1.855 & 1.852 & 1.174 & 2.639 & & \\
\hline & & $\mathrm{Cu}-\mathrm{C}$ & $\mathrm{C}-\mathrm{N}$ & $\mathrm{N}-\mathrm{Cu}$ & $\mathrm{Cu}-\mathrm{C}$ & $\mathrm{C}-\mathrm{N}$ & $\mathrm{N}-\mathrm{Cu}$ & $\mathrm{Cu}-\mathrm{C}$ & $\mathrm{C}-\mathrm{N}$ & $\mathrm{N}-\mathrm{Cu}$ & $\mathrm{Cu}-\mathrm{C}$ & $\mathrm{C}-\mathrm{N}$ & $\mathrm{N}-\mathrm{K}$ \\
\hline $\mathbf{7}$ & anion & 1.874 & 1.173 & 1.855 & 1.849 & 1.173 & 1.856 & 1.850 & 1.173 & 1.859 & 1.856 & 1.174 \\
& K-capped & 1.874 & 1.172 & 1.855 & 1.847 & 1.173 & 1.855 & 1.847 & 1.173 & 1.855 & 1.852 & 1.174 & 2.638 \\
\hline
\end{tabular}

Table 2. DFT(BLYP)/BSI energies $(\mathrm{kcal} / \mathrm{mol})$ of the isomers of the $\mathrm{CuCN}$ model chains.

\begin{tabular}{|c|c|c|c|c|c|c|c|c|c|}
\hline & \multicolumn{3}{|c|}{$\Delta \mathrm{E}+\mathrm{ZPE}$} & \multicolumn{6}{|c|}{$\Delta \mathrm{E}+\mathrm{ZPE}$} \\
\hline $\mathrm{n}=1$ & bare & K-cap & $\mathrm{n}=3$ & bare & K-cap & $\mathrm{n}=4$ & K-cap & $\mathrm{n}=5$ & K-cap \\
\hline $\mathbf{1} \equiv \mathbf{1}_{\mathbf{R L}}$ & 0.0 & 0.0 & $\mathbf{3} \equiv \mathbf{3}_{\text {RRLL }}$ & 0.0 & 0.0 & 4RRRRL $=$ 4RLLLL & 0.0 & $5 \equiv 5_{\text {RRRLLL }}$ & 0.0 \\
\hline $\mathbf{1}_{\mathrm{LR}}$ & 7.56 & 19.76 & 3LLRR & 16.54 & 19.84 & $\mathbf{4}_{\mathrm{RRLRL}}=\mathbf{4}_{\mathrm{RLRLL}}$ & 1.50 & 5RLLRRL & 1.53 \\
\hline \multirow[t]{8}{*}{$\mathbf{1}_{\mathrm{RR}}=\mathbf{1}_{\mathrm{LL}}$} & 7.05 & 9.16 & 3RLRL & 1.07 & 1.46 & $\mathbf{4}_{\mathrm{RRRLL}}=\mathbf{4}_{\mathrm{RRLLL}}$ & 0.01 & 5RRLRLL & 1.50 \\
\hline & & & 3LRLR & 18.39 & 21.27 & $\mathbf{4}_{\mathrm{RLLRL}}=\mathbf{4}_{\mathrm{RLRRL}}$ & 1.51 & 5RLRLRL & 2.98 \\
\hline & & & $\mathbf{3}_{\text {RRRR }}=\mathbf{3}_{\text {LLLL }}$ & 9.16 & 9.16 & & & $5_{\text {RRRRRL }}=5$ RLLLLL & 0.00 \\
\hline & & & $\mathbf{3}_{\text {RLLR }}=\mathbf{3}_{\text {LRRL }}$ & 8.99 & 10.64 & & & 5RRLLRL $=5$ RLRRLL & 1.51 \\
\hline & & & 3 RRRL $=\mathbf{3}_{\text {RLLL }}$ & -0.21 & -0.02 & & & $5_{\text {RRRRLL }}=5_{\text {RRLLLL }}$ & 0.01 \\
\hline & & & 3LLLR $=$ 3LRRR & 16.72 & 19.80 & & & $5_{\text {RLLLRL }}=5$ RLRRRL & 1.51 \\
\hline & & & $\mathbf{3}_{\text {RLRR }}=\mathbf{3}_{\text {LRLL }}$ & 8.80 & 10.65 & & & $5_{\text {RRLRRL }}=5_{\text {RLLRLL }}$ & 1.52 \\
\hline & & & 3 $_{\text {RRLR }}=$ 3 $_{\text {LRLL }}$ & 9.20 & 10.64 & & & $5_{\text {RRRLRL }}=5_{\text {RLRLLL }}$ & 1.49 \\
\hline
\end{tabular}


Table 3. BLYP wavelengths (nm) and oscillator strengths (f) for $\pi-\pi$ transitions (TD-DFT) and adiabatic $\mathrm{S}_{0}-\mathrm{T}$ gaps (nm) for bare anionic and $\mathrm{K}$-capped symmetric chains $\left[\mathrm{Cu}_{\mathrm{n}}(\mathrm{CN})_{\mathrm{n}+1}\right]^{-}(\mathrm{n}=1,2,3,4,5,7)$

\begin{tabular}{|c|c|c|c|c|c|c|c|c|c|c|c|c|}
\hline $\mathrm{n}$ & & $\lambda, \mathrm{nm}$ & & & & & & & & & $\begin{array}{l}\mathrm{S}_{0}-\mathrm{T} \text { gap, } \mathrm{nm} \\
\text { (linear) }\end{array}$ & $\begin{array}{l}\mathrm{S}_{0}-\mathrm{T} \text { gap, nm } \\
\text { (bent) }\end{array}$ \\
\hline \multirow[t]{4}{*}{1} & anion & 237.8 & & & & & & & & & & \\
\hline & $\mathrm{f}$ & 0.21 & & & & & & & & & & \\
\hline & K-capped & 232.2 & & & & & & & & & 262.9 & 330.5 \\
\hline & f & 0.39 & & & & & & & & & & \\
\hline \multirow[t]{4}{*}{2} & anion & 271.1 & 246.7 & & & & & & & & & \\
\hline & $\mathrm{f}$ & 0.48 & 0.20 & & & & & & & & & \\
\hline & K-capped & 264.9 & 244.5 & & & & & & & & & \\
\hline & f & 0.60 & 0.18 & & & & & & & & & \\
\hline \multirow[t]{4}{*}{3} & anion & 314.2 & 246.0 & 243.1 & 230.5 & & & & & & & \\
\hline & $\mathrm{f}$ & 0.47 & 0.26 & 0.30 & 0.26 & & & & & & & \\
\hline & K-capped & 275.6 & 240.6 & 238.6 & & & & & & & 296.9 & 328.1 \\
\hline & f & 0.78 & 0.50 & 0.11 & & & & & & & & \\
\hline \multirow[t]{4}{*}{4} & anion & 344.6 & 320.7 & 286.1 & 263.0 & 259.8 & 249.3 & & & & & \\
\hline & $\mathrm{f}$ & 0.13 & 0.13 & 0.16 & 0.51 & 0.26 & 0.17 & & & & & \\
\hline & K-capped & 288.6 & 271.8 & 256.3 & 239.9 & 238.1 & & & & & & \\
\hline & $\mathrm{f}$ & 0.40 & 0.66 & 0.44 & 0.11 & 0.11 & & & & & & \\
\hline \multirow[t]{4}{*}{5} & anion & 398.2 & 315.2 & 291.0 & 283.6 & 273.1 & 246.3 & 243.4 & 236.9 & & & \\
\hline & $\mathrm{f}$ & 0.12 & 0.17 & 0.27 & 0.77 & 0.17 & 0.24 & 0.16 & 0.34 & & & \\
\hline & K-capped & 292.6 & 268.9 & 265.5 & 249.5 & 242.7 & & & & & 304.5 & 328.1 \\
\hline & f & 0.70 & 0.60 & 0.49 & 0.14 & 0.30 & & & & & & \\
\hline \multirow[t]{4}{*}{7} & anion & 458.5 & 380.1 & 344.1 & 322.4 & 305.7 & 281.5 & 278.8 & 271.9 & 267.1 & & \\
\hline & $\mathrm{f}$ & 0.03 & 0.08 & 0.14 & 0.13 & 0.36 & 0.15 & 0.79 & 0.50 & 0.18 & & \\
\hline & K-capped & 297.9 & 282.0 & 280.1 & 268.1 & 263.5 & 258.6 & 257.1 & & & & \\
\hline & f & 0.71 & 0.43 & 0.75 & 0.14 & 0.38 & 0.37 & 0.14 & & & & \\
\hline
\end{tabular}




\title{
References
}

\begin{abstract}
${ }^{1}$ Ropp, R.C. Luminescence and the Solid State, 2nd ed., Elsevier: Amsterdam, 2004.
2 (a) Exstrom, C. L.; Sowa, Jr., J. L.; Daws, C. A.; Janzen, D.; Mann, K. R.; Moore, G. A.; Stewart, F. F. Chem. Mater. 1995, 7, 15. (b) Daws, C. A.; Exstrom, C. L.; Sowa, Jr., J. L.; Mann, K. R. Chem. Mater. 1997, 9, 363. (c) Vickery, J. C.; Olmstead, M. M.; Fung, E. Y.; Balch, A. L. Angew. Chem. Int. Ed. 1997, 36, 1179. (d) Cariati, E.; Bu, X.; Ford, P. C. Chem. Mater. 2000, 12, 3385. (e) Drew, S. M.; Janzen, D. E.; Buss, C. E.; MacEwen, D. I.; Dublin, K. I.; Mann, K. R. J. Am. Chem. Soc. 2001, 123, 8414. (f) Buss, C. E.; Mann, K. R. J. Am. Chem. Soc. 2002, 124, 1031. (g) Fernández, E. J.; López-de-Luzuriaga, J. M.; Monge, M.; Olmos, M. E.; Pérez, J.; Laguna, A.; Mohamed, A. A.; Fackler, Jr., J. P. J. Am. Chem. Soc. 2003, 125, 2022. (h) Lu, W.; Chan, M. C. W.; Zhu, N.; Che, C.-M.; He, Z.; Wong, K.-Y. Chem.-Eur. J. 2003, 9, 6155 .
\end{abstract}

${ }^{3}$ (a) Tronic, T. A.; deKrafft, K. E.; Lim, M. J.; Ley, A. N.; Pike, R. D. Inorg. Chem. 2007, 46, 8897. (b) Pike, R. D.; deKrafft, K. E.; Ley, A. N.; Tronic, T. A. Chem. Commun. 2007, 3732. (c) Lim, M. J.; Murray, C. A.; Tronic, T. A.; deKrafft, K. E.; Ley, A. N.; deButts, J. C.; Pike, R. D.; Lu, H.; Patterson, H. H. Inorg. Chem. 2008, 47, 6931.

${ }^{4}$ Hibble, S. J.; Eversfield, S. G.; Cowley, A. R.; Chippendale, A. M. Angew. Chem. Int. Ed. 2004, 43, 628.

${ }^{5}$ Hibble, S. J.; Cheyne, S. M.; Hannon, A. C.; Eversfield, S. G. Inorg. Chem. 2002, 41, 4990.

${ }^{6}$ (a) Pyykkö, P. Chem. Rev. 1997, 97, 597. (b) Hermann, H. L.; Bosch, G.; Schwerdtfeger, P. Chem.-Eur. J. 2001, 7, 5334.

${ }^{7}$ Bowmaker, G. A.; Lim, K. C.; Skelton, B. W.; White, A. H. Z. Naturforsch. B 2004, 59, 1264.

8 (a) Horváth, A.; Stevenson, K. L. Inorg. Chem. 1993, 32, 2225. (b) Horváth, A.; Wood, C. E.; Stevenson, K. L. Inorg. Chem. 1994, 33, 5351.

${ }^{9}$ Ford, P. C.; Cariati, E.; Bourassa, J. Chem. Rev., 1999, 99, 3625 and references cited therein.

${ }^{10}$ (a) Chesnut, D. J.; Kusnetzow, A.; Zubieta, J. J. Chem. Soc., Dalton Trans. 1998, 4081. (b) Stocker, F. B.; Staeva, T. P.; Rienstra, C. M.; Britton, D. Inorg. Chem. 1999, 38, 984. (c) Chesnut, D. J.; Kusnetzow, A.; Birge, R. R.; Zubieta, J. Inorg. Chem. 1999, 38, 2663. (d) Chesnut, D. J.; Kusnetzow, A.; Birge, R. R.; Zubieta, J. Inorg. Chem. 1999, $38,5484$. (e) Chesnut, D. J.; Plewak, D.; Zubieta, J. J. Chem. Soc., Dalton Trans. 2001, 2567. (f) Teichert, O.; Sheldrick, W. S. Z. Anorg. Allg. Chem. 2000, 626, 1509. (g) Teichert, O.; Sheldrick, W. S. Z. Anorg. Allg. Chem. 1999, 625, 1860. (h) Greve, J.; Näther, C. Z. Naturforsch. 2004, 59b, 1325. (i) Mühle, J.; Sheldrick, W. S. Z. Anorg. Allg. Chem. 2003, 629, 2097. (j) Kromp, T.; Sheldrick, W. S.; Näther, C. Z. Anorg. Allg. Chem. 2003, 629, 45. (l) Hibble, S. J.; Chippindale, A. M. Z. Anorg. Allg. Chem. 2005, 631, 542. (m) Kuhlman, R.; Schimek, G. L.; Kolis, J. W. Polyhedron 1999, $18,1379$.

11 Dreuw, A.; Head-Gordon, M. Chem. Rev. 2005, 105, 4009.

${ }^{12}$ (a) van Gisbergen, S. J. A.; Rosa, A.; Ricciardi, G.; Baerends, E. J. J. Chem. Phys. 1999, 111, 2499. (b) Cai, Z.L.; Sendt, K.; Reimers, J. R. J. Chem. Phys. 2002, 117, 5543.

${ }^{13}$ (a) Dunietz, B.D.; Dreuw, A.; Head-Gordon, M. J. Phys. Chem. B 2003, 107, 5623. (b) Dreuw, A.; Fleming, G.R.; Head-Gordon, M. Phys. Chem. Chem. Phys. 2003 ,5, 3247.

${ }^{14}$ Grimme, S.; Parac, M. CHEMPHYSCHEM 2003, 292.

${ }^{15}$ (a) Salzner, U. J. Chem. Theor. Comput. 2007, 3, 219. (b) Salzner, U. J. Chem. Theor. Comput. 2007, 3, 1143.

${ }^{16}$ Peach, M. J. G.; Tellgren, E. I.; Salek, P.; Helgaker, T.; Tozer, D. J. J. Phys. Chem. A 2007, 111, 11930.

${ }^{17}$ Vlček, A.; Záliš, S. Coord. Chem. Rev. 2007, 251, 258 and references therein. 
${ }^{18}$ Gaussian 03, Revision C.02, Frisch, M. J.; Trucks, G. W.; Schlegel, H. B.; Scuseria, G. E.; Robb, M. A.; Cheeseman, J. R.; Montgomery, Jr., J. A.; Vreven, T.; Kudin, K. N.; Burant, J. C.; Millam, J. M.; Iyengar, S. S.; Tomasi, J.; Barone, V.; Mennucci, B.; Cossi, M.; Scalmani, G.; Rega, N.; Petersson, G. A.; Nakatsuji, H.; Hada, M.; Ehara, M.; Toyota, K.; Fukuda, R.; Hasegawa, J.; Ishida, M.; Nakajima, T.; Honda, Y.; Kitao, O.; Nakai, H.; Klene, M.; Li, X.; Knox, J. E.; Hratchian, H. P.; Cross, J. B.; Bakken, V.; Adamo, C.; Jaramillo, J.; Gomperts, R.;

Stratmann, R. E.; Yazyev, O.; Austin, A. J.; Cammi, R.; Pomelli, C.; Ochterski, J. W.; Ayala, P. Y.; Morokuma, K.; Voth, G. A.; Salvador, P.; Dannenberg, J. J.; Zakrzewski, V. G.; Dapprich, S.; Daniels, A. D.; Strain, M. C.; Farkas, O.; Malick, D. K.; Rabuck, A. D.; Raghavachari, K.; Foresman, J. B.; Ortiz, J. V.; Cui, Q.; Baboul, A. G.; Clifford, S.; Cioslowski, J.; Stefanov, B. B.; Liu, G.; Liashenko, A.; Piskorz, P.; Komaromi, I.; Martin, R. L.; Fox, D. J.; Keith, T.; Al-Laham, M. A.; Peng, C. Y.; Nanayakkara, A.; Challacombe, M.; Gill, P. M. W.; Johnson, B.; Chen, W.; Wong, M. W.; Gonzalez, C.; and Pople, J. A.; Gaussian, Inc., Wallingford CT, 2004.

${ }^{19}$ (a) Slater, J. C. Quantum Theory of Molecules and Solids. Vol. 4. McGraw-Hill, New York: 1974. (b) Vosko, S. H.; Wilk, L.; Nusair, M. Can. J. Phys. 1980, 58, 1200.

${ }^{20}$ Becke, A.D. Phys. Rev. A 1988, 38, 3098.

${ }^{21}$ (a) Lee, C.; Yang, W.; Parr, R. G. Phys. Rev. 1988, B37, 785. (b) Colle, R.; Salvetti, O. Theor. Chim. Acta 1975, $37,329$.

${ }^{22}$ Perdew, J. P.; Phys. Rev. B 1986, 33, 8822.

${ }^{23}$ Boese, A. D.; Handy, N.C. J. Chem. Phys. 2001, 114, 5497.

${ }^{24}$ Adamo, C.; Barone, V. J. Chem. Phys. 1998, 108, 664.

${ }^{25}$ Hurley, M. M.; Pacios, L.F.; Christiansen, P. A.; Ross, R. B.; Ermler, W.C. J. Chem. Phys. 1986, 84, 6840.

${ }^{26}$ Couty, M.; Hall, M. B. J. Comput. Chem. 1996, 17, 1359.

${ }^{27}$ Dunning, T. H. J. Chem. Phys. 1971, 55, 716.

${ }^{28}$ Hay, P.J.; Wadt, W.R. J. Chem. Phys. 1985, 82, 299.

${ }^{29}$ Monocapped models avoid the overall positive charge on the chains but leads to an asymmetric chemical environment at the ends of the chain and TD-DFT excitation bands inconsistent with the experimental spectrum. See Supplementary Materials.

${ }^{30}$ The number of possible isomers is $2^{n+1}$, where $n+1$ is the number of cyanide ligands in the chain.

${ }^{31}$ Stevenson, K. L.; Jarboe, J. H.; Langmeyer, S. A.; Acra, T.W. Inorg. Chem. 2003, 42, 3559.

${ }^{32}$ Horváth, A.; Zsilák, Z.; Papp, S. J. Photochem. Photobiol. A 1989, 50, 129.

${ }^{33}$ Bayse, C.A. unpublished data. These results also show a significant dependence of the excitation energy upon the basis set. (BLYP: 8.18 (6-31G*), 7.65 (TZVP), 7.85 (cc-pVTZ) ; B3LYP: 8.51 (6-31G*), ${ }^{16} 7.99$ (TZVP), 8.18 (ccpVTZ) eV)

${ }^{34}$ Vázquez-Mayagoitia, Á.; Vargas, R.; Nichols, J. A.; Fuentealba, P.; Garza, J. Chem. Phys. Lett. $2006,419,207$.

${ }^{35}$ Arvapally, R. K.; Sinha, P.; Hettiarachchi, S. R.; Coker, N. L.; Bedel, C. E.; Patterson, H. H.; Elder, R. C.; Wilson, A. K.; Omary, M. A. J. Phys. Chem. C 2007, 111, 10689. 
${ }^{36}$ (a) Lin, Y.-Y.; Lai, S.-W.; Che, C.-M.; Fu, W.-F.; Zhou; Z.-Y.; Zhu, N. Inorg. Chem. 2005, 44, 1511. (b) Liu, X.; Guo, G.-C.; Wu, A.-Q.; Cai, L.-Z.; Huang, J.-S. Inorg. Chem. 2005, 44, 4282. (c) Lin, J.-D.; Li, Z.-H.; Li, T.; Li, J.R.; Du, S.-W. Inorg. Chem. Commun. 2006, 9, 675. (d) Xu, Y.; Ren, Z.-G.; Li, H-X.; Zhang, W.-H.; Chen, J.-X.; Zhang, Y.; Lang, J.-P. J. Mol. Struct. 2006, 782, 150. 